Journal of Clinical Investigation

Vol. 42, No. 5,1963

\title{
ESOPHAGEAL MOTOR ABNORMALITIES INDUCED BY ACID PERFUSION IN PATIENTS WITH HEARTBURN *
}

\author{
By CHARLES I. SIEGEL AND THOMAS R. HENDRIX $\dagger$ \\ (From the Department of Medicine, The Johns Hopkins University School of Medicine, \\ Baltimore, $M d$.)
}

(Submitted for publication July 2, 1962; accepted January 24, 1963)

The clinical diagnosis of esophagitis is suggested by the presence of severe heartburn which is aggravated by the recumbent position. The symptom is generally worse after eating and is relieved by antacids. It is generally held that increased reflux of gastric contents leads to the development of esophagitis and that the pain is associated with an inflammatory process. In many patients with symptoms that suggest a diagnosis of esophagitis, however, there is, no endoscopic or histologic evidence of inflammation. The poor correlation between the clinical diagnosis of esophagitis and the endoscopic and histologic observations led to an investigation of esophageal motor function in these patients.

\section{METHOD AND MATERIALS}

Twenty-five patients with the clinical diagnosis of esophagitis were studied. The clinical diagnosis was based on the following criteria: recurrent burning retrosternal pain, which was more severe after eating, aggravated by the recumbent position, and improved by antacids. Esophagoscopy was performed in all patients. Specific features noted were mucosal reddening, granularity, erosion, ulceration, stricture, and the presence and degree of gastroesophageal reflux. Esophageal biopsies were obtained from an involved area if gross changes were observed and from the distal $4 \mathrm{~cm}$ of esophagus when no endoscopic abnormalities were present. $\mathrm{X}$ rays of the upper gastrointestinal tract with special attention to the gastroesophageal junction were obtained in all patients. Radiographic evidence of hiatus hernia and esophageal reflux was sought with the patients in the Trendelenburg position. Acid perfusion of the lower esophagus, with the technique to be described, was performed on all patients.

These patients were compared with a control group of 25 patients who had none of the criteria described above for the clinical diagnosis of esophagitis. The control group, some of whom had coronary artery disease, were

* This investigation was supported by U. S. Public Health Service research grant A-1687(C4) and U. S. Public Health Service training grant 2A-5095(C4).

$\dagger$ John and Mary R. Markle Scholar. not all esophagoscoped, but acid-perfusion studies and radiologic studies were performed in all. A tabulated description of the heartburn and the control groups is found in Tables I and II.

Pathologic findings and motility records were graded without knowledge of the clinical or endoscopic findings. On the other hand, the esophagoscopist was usually under the impression that the clinical diagnosis was esophagitis.

Esophageal motor studies were performed with the subject supine. Three open-tipped, water-filled polyvinyl catheters with the tips placed $5 \mathrm{~cm}$ apart were introduced into the stomach. The catheters were connected to external transducers that were leveled at the posterior axillary line, and simultaneous, four-channel, direct-writing recording was performed. ${ }^{1}$ The catheters were withdrawn into the esophagus in $1-\mathrm{cm}$ steps to measure the resting tone of the lower esophageal sphincter. After the resting pressure of the lower esophageal sphincter and the motor response of the lower esophagus to swallowing were recorded, the distal tip was withdrawn to a position $5 \mathrm{~cm}$ above the lower esophageal sphincter. The acid-perfusion studies were then performed as indicated schematically in Figure 1. Continuous perfusion of the esophagus was performed through the proximal catheter for three test periods, first with isotonic saline, second with $0.1 \mathrm{~N} \mathrm{HCl}$, and third with saline. Motor recording was performed through the middle and distal catheter tips. Catheters were flushed only if dampening of excursions appeared. The perfusion periods with saline were 10 minutes long, and the perfusion with $0.1 \mathrm{~N} \mathrm{HCl}$ was continued for 20 minutes, or less if the patient's symptoms were exactly duplicated after a shorter interval of acid perfusion. The rate of perfusion was 90 to 120 drops per minute, and at this rate secondary peristalsis was only rarely initiated. The initiation of perfusion and the change from one solution to another were performed so that the patient was unaware of these maneuvers. Spontaneous motor activity as well as the response to "dry" swallows (the bolus consisting of the patient's saliva rather than a sip of water) were monitored continuously throughout all test periods. The specific intent was to determine whether acid-induced heartburn was associated with motor abnormalities of the lower esophagus.

${ }^{1}$ Sanborn differential pressure transducers, model 267 $B$, were employed in these studies. The recordings were made with a Sanborn four-channel, direct-writing recorder. 
TABLE I

Heartburn group

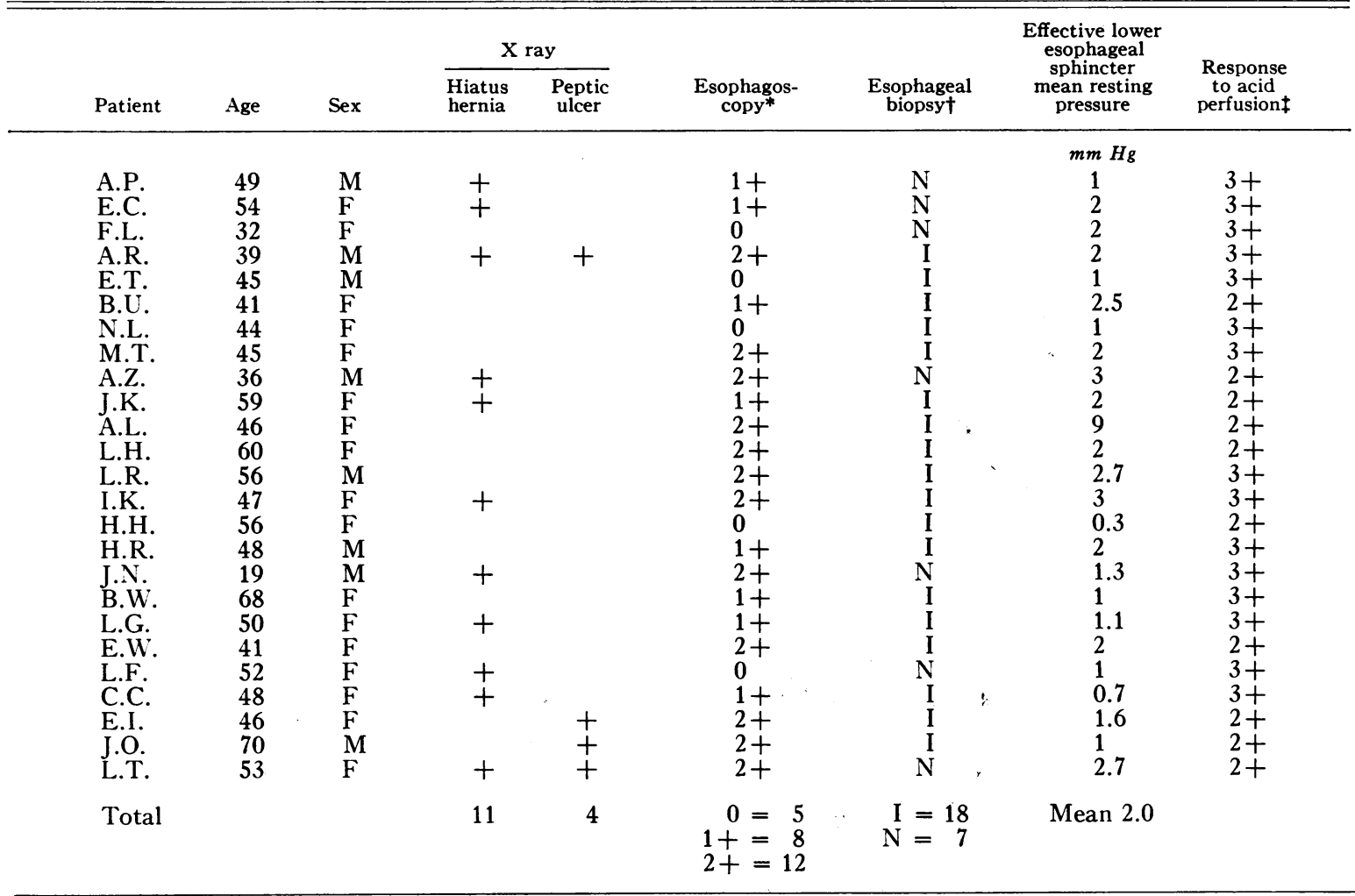

${ }^{*} 0=$ no abnormality; $1+=$ reddening of the mucosá; and $2+=$ granularity or friability of the mucosa, or both

$\dagger \mathrm{I}=$ inflammation, $\mathrm{N}=$ normal.

$\ddagger 3+=$ duplication of the patient's symptoms; $2+=$ symptoms qualitatively similar but less severe; and $1+$ $=$ symptoms unlike the patient's spontaneous symptoms.



Fig. 1. Schematic Representation of technique of acid Perfusion. The uppermost catheter is employed for perfusion. By a threeway stopcock, the perfusing solution may be changed without knowledge of the patient. Continuous, simultaneous recording is performed through the two distal catheters. 

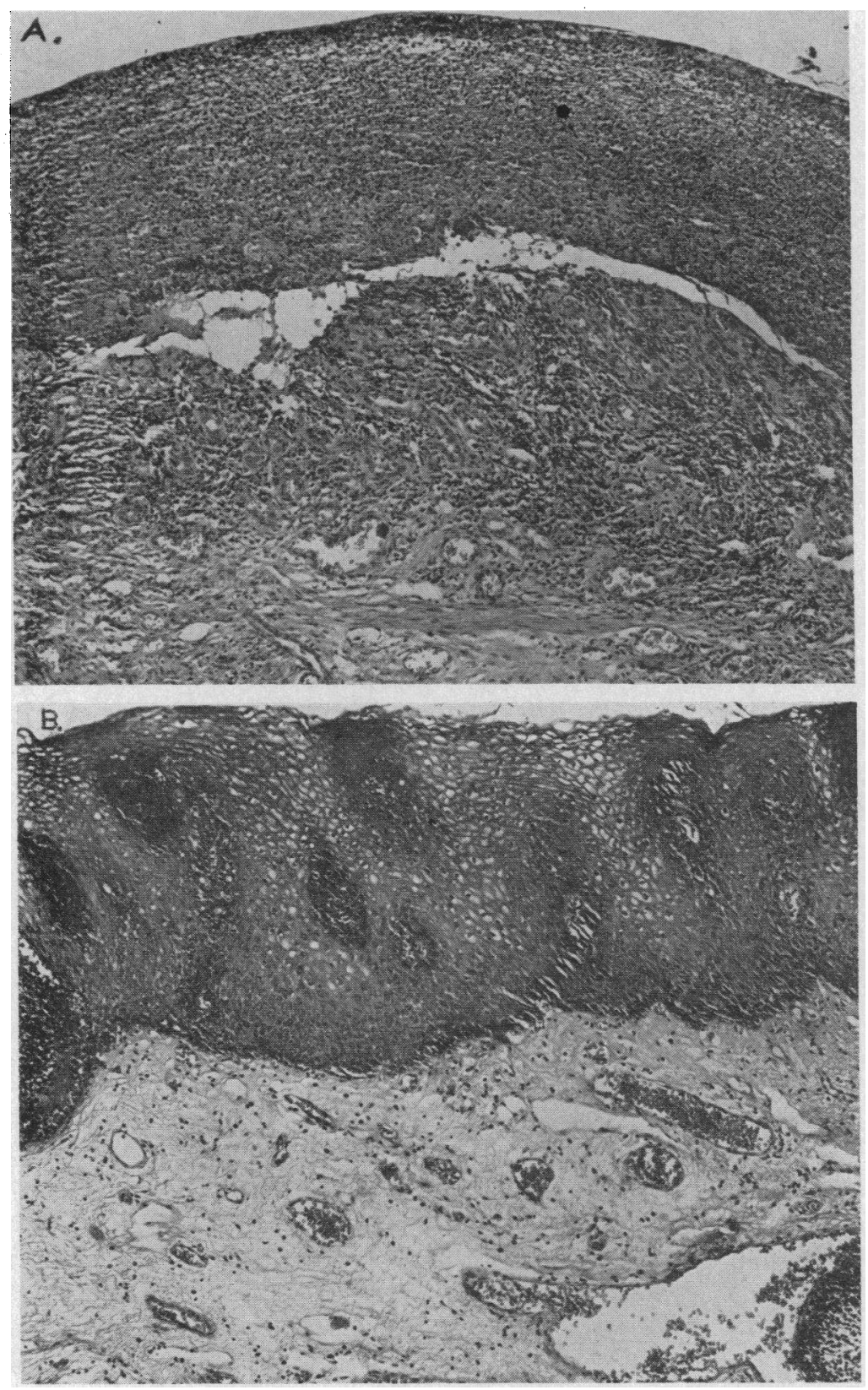

Fig. 2. Three biopsies of the lower esophagus. A. The biopsy was obtained from a patient who was symptom free at the time of and for several months before biopsy. This biopsy shows severe changes consisting of necrosis of the epithelium with pseudomembrane formation and severe subacute and chronic inflammatory changes in the submucosa. B. The biopsy was obtained from a patient with moderate symptoms. The changes observed in this biopsy consist of a moderately increased vascularity of the epithelium and the lamina propria with a minimal increase in mononuclear cells. C. The biopsy was obtained from a patient who was disabled by severe symptoms. Her biopsy was virtually normal. This lack of correlation between histologic abnormality and the occurrence of symptoms was frequently encountered as described in the text and summarized in Table III. Magnification $100 \times$. 


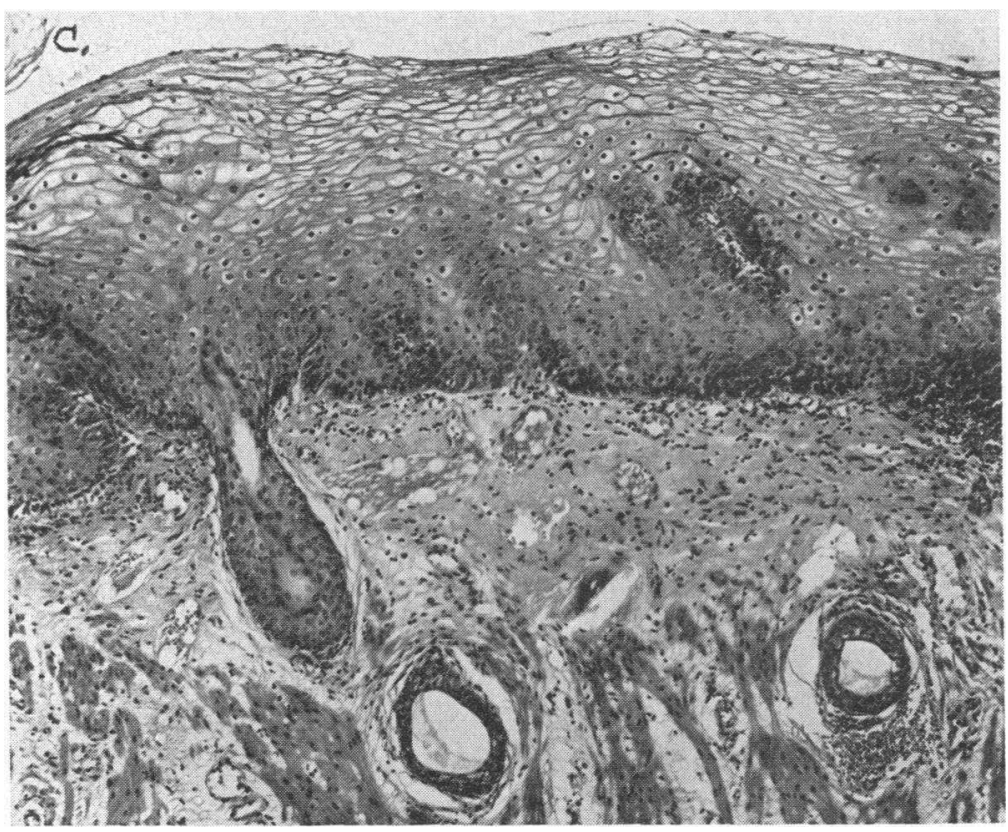

FIG. 2-(Continued)

TABLE II

Control group

\begin{tabular}{|c|c|c|c|c|c|c|c|c|}
\hline \multirow[b]{2}{*}{ Patient } & \multirow[b]{2}{*}{ Age } & \multirow[b]{2}{*}{ Sex } & \multicolumn{2}{|c|}{$\mathrm{X}$ ray } & \multirow[b]{2}{*}{$\begin{array}{c}\text { Esoph- } \\
\text { agoscopy* }\end{array}$} & \multirow[b]{2}{*}{$\begin{array}{c}\text { Esophageal } \\
\text { biopsyt }\end{array}$} & \multirow{2}{*}{$\begin{array}{l}\text { Effective lower } \\
\text { esophageal } \\
\text { sphincter } \\
\text { mean resting } \\
\text { pressure }\end{array}$} & \multirow[b]{2}{*}{$\begin{array}{c}\text { Response } \\
\text { to acid } \\
\text { perfusion } \ddagger\end{array}$} \\
\hline & & & $\begin{array}{l}\text { Hiatus } \\
\text { hernia }\end{array}$ & $\begin{array}{l}\text { Peptic } \\
\text { ulcer }\end{array}$ & & & & \\
\hline & & & & & & & $m m \mathrm{Hg}$ & \\
\hline R.W. & 41 & $\mathrm{~F}$ & & & 0 & & 7 & 0 \\
\hline A.B. & 51 & $\mathrm{~F}$ & & & 0 & $\mathrm{~N}$ & 3.3 & 0 \\
\hline J.B. & 62 & M & & & 0 & $\mathrm{~N}$ & 2 & 0 \\
\hline B.G. & 37 & $\mathrm{~F}$ & & & 0 & $\mathrm{~N}$ & 7.7 & 0 \\
\hline R.B. & 69 & $\mathrm{~F}$ & & + & & & 6.3 & 0 \\
\hline E.H. & 44 & $\mathrm{~F}$ & & & 0 & $\mathrm{~N}$ & 9 & 0 \\
\hline N.J. & 46 & M & + & & & & 7.7 & 0 \\
\hline R.S. & 67 & $\mathrm{~F}$ & + & & & & 3.5 & 0 \\
\hline L.S. & 52 & $\mathrm{~F}$ & + & & $2+$ & I & 2 & 0 \\
\hline W.S. & 44 & $\mathrm{M}$ & & & & & 6 & 0 \\
\hline H.D. & 48 & M & & & $1+$ & & 2 & 0 \\
\hline L.S. & 50 & $\mathrm{~F}$ & & & $2+$ & $\mathrm{N}$ & 3.7 & 0 \\
\hline R.G. & 35 & $\mathrm{~F}$ & & & & & 1.8 & 0 \\
\hline A.F. & 64 & $M$ & & & & & 5.8 & 0 \\
\hline P.S. & 43 & M & + & + & & & 1.6 & 0 \\
\hline IV.S. & 45 & M & & & & & 6.8 & 0 \\
\hline E.L. & 45 & M & & & & & 5.5 & 0 \\
\hline M.R. & 51 & $\mathrm{~F}$ & & & & & 6 & 0 \\
\hline E.W. & 61 & $\mathrm{~F}$ & & & $1+$ & 1 & 6 & 0 \\
\hline M.H. & 63 & $\mathrm{~F}$ & & & & & 6.5 & 0 \\
\hline W.S. & 52 & $\mathbf{M}$ & & & & & 6 & 0 \\
\hline L.B. & 70 & M & & & & & 6 & 0 \\
\hline E.T. & 55 & $\mathrm{~F}$ & & & & & 5.5 & 0 \\
\hline J.C. & 33 & $\mathrm{~F}$ & & & & & 7.6 & 0 \\
\hline J.W. & 32 & $\mathrm{M}$ & & & $1+$ & I & 3 & 0 \\
\hline Total & & & 4 & 2 & $\begin{array}{r}0=5 \\
1+=3 \\
2+=2\end{array}$ & $\begin{aligned} I & =3 \\
N & =5\end{aligned}$ & Mean 5.1 & \\
\hline
\end{tabular}

$*^{*} 0=$ no abnormality $; 1+=$ reddening of the mucosa ; and $2+=$ granularity or friability of the mucosa, or both. $\dagger \mathrm{I}=$ Inflammation, $\mathrm{N}=$ normal.

$\ddagger 3+=$ duplication of the patient's symptoms; $2+=$ symptoms qualitatively similar but less severe; and $1+$ $=$ symptoms unlike the patient's spontaneous symptoms, $0=$ no response. 
TABLE III

Histologic and acid-perfusion data in heartburn and control groups

\begin{tabular}{lcccc}
\hline \hline & \multirow{2}{*}{$\begin{array}{c}\text { Number } \\
\text { of } \\
\text { patients }\end{array}$} & $\begin{array}{c}\text { Positive } \\
\text { acid } \\
\text { perfusion }\end{array}$ & \multicolumn{2}{c}{ Biopsy } \\
\cline { 4 - 5 } & 25 & 25 & 18 & 7 \\
Heartburn & 25 & 0 & 3 & 5 \\
Control & 25 & 0 Eshagitis & Normal \\
\hline
\end{tabular}

RESULTS

Correlation of esophageal symptoms with gross and histologic evidence of inflammation. Gross and histologic evidence of esophageal inflammation did not correlate either by its presence or intensity with the symptoms of heartburn. Several biopsies with the most severe inflammatory changes were obtained from patients who were asymptomatic. Conversely, patients with severe symptoms occasionally had normal biopsies. Three biopsies where symptoms actually bore an inverse relationship to severity of inflammatory changes are shown in Figure 2. Of the group of 25 patients with heartburn of such severity that

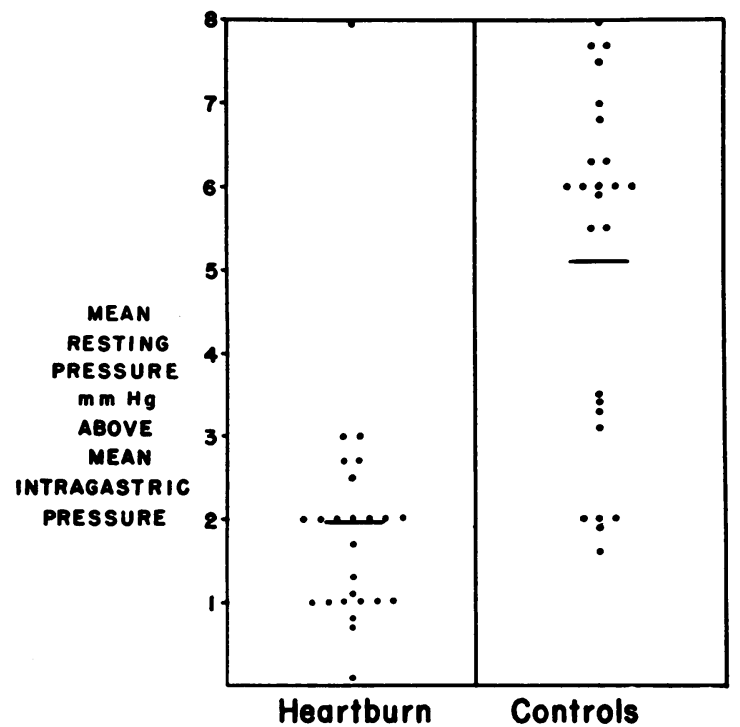

Fig. 3. EFfective Resting PRESSURE IN THE LOWER ESOPHAGEAL SPHINCTER (MEAN RESTING INTRASPHINCTERIC PRESSURE MINUS MEAN INTRAGASTRIC PRESSURE) IS PLOTTED FOR THE HEARTBURN PATIENTS AND FOR THE CONTROL GROUP. Twenty-four of 25 patients in the heartburn group had sphincteric pressure of $3 \mathrm{~mm} \mathrm{Hg}$ or less in excess of intragastric pressure. In 19 of the $25 \mathrm{mem}-$ bers of the control group, this value was in excess of 3 $\mathrm{mm} \mathrm{Hg}$. The mean for each group is plotted by a transverse line. it was ascribed to esophagitis, 18 had esophageal biopsies showing inflammatory changes, while seven had normal biopsies. From Tables I and II it can be seen that the esophagoscopic evaluation of mucosal inflammation does not closely parallel the actual histologic findings. Clinically, the patients with histologic evidence of inflammation could not be differentiated from those with normal findings. Ten of the 25 patients in the control group were esophagoscoped. Five of the ten showed reddening of the esophageal mucosa, and in two patients, this was accompanied by granularity of the mucosa. Three of the patients showing endoscopic abnormalities had mild to moderate chronic inflammatory changes on biopsy. None of these patients had heartburn or other symptoms of esophagitis (Table III).

TABLE IV

Acid-induced esophageal motor abnormalities in heartburn and control groups

\begin{tabular}{lccccc}
\hline & $\begin{array}{c}\text { Num- } \\
\text { ber } \\
\text { of } \\
\text { patients activity }\end{array}$ & $\begin{array}{c}\text { Syn- } \\
\text { chro- } \\
\text { nous } \\
\text { Group }\end{array}$ & $\begin{array}{c}\text { In- } \\
\text { creased } \\
\text { luminal } \\
\text { pressure }\end{array}$ & $\begin{array}{c}\text { Pro- } \\
\text { longed } \\
\text { peri- } \\
\text { stalsis }\end{array}$ & $\begin{array}{c}\text { Total } \\
\text { acid- } \\
\text { induced } \\
\text { motor } \\
\text { abnor- } \\
\text { malities }\end{array}$ \\
\hline $\begin{array}{l}\text { Heartburn } \\
\text { Control }\end{array}$ & 25 & 23 & 24 & 24 & 25 \\
25 & 2 & 0 & 2 & $2 *$ \\
\hline
\end{tabular}

* Four control patients had isolated motor abnormalities. In two patients, these were seen only in the acid-perfusion period. In the other two, the abnormalities appeared sporadically in both saline and acid-perfusion periods.

Correlation of esophageal symptoms with resting pressure in the lower esophageal sphincter. The resting pressure of the lower esophageal sphincter was measured at least three times in each of the patients and controls by withdrawing the three catheter tips through the area of the sphincter in $1-\mathrm{cm}$ steps. The resting pressure recorded at each level was the average of the endinspiratory and end-expiratory pressures. The mean resting pressure of the lower esophageal sphincter was obtained by averaging all technically satisfactory runs. The mean intrasphincteric pressure exceeded mean intragastric pressure by more than $3 \mathrm{~mm} \mathrm{Hg}$ in only one of the $25 \mathrm{pa}$ tients with esophageal symptoms, whereas the difference was greater than $3 \mathrm{~mm} \mathrm{Hg}$ in 19 of the 25 controls (Figure 3 ).

Correlation of symptoms with results of acidperfusion study and description of motor abnormalities observed. In all 25 patients with 
SALINE NO PAIN

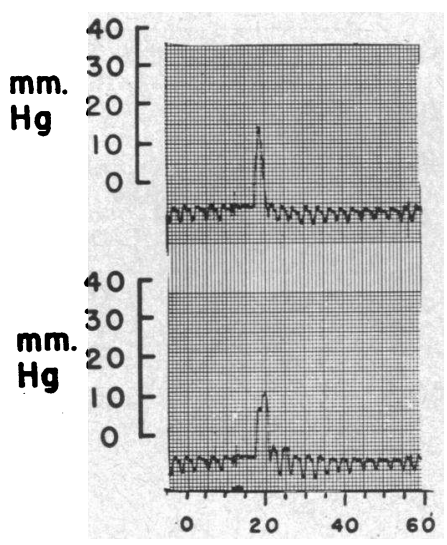

\section{$0.1 \mathrm{~N} \mathrm{HCl}$} PAIN

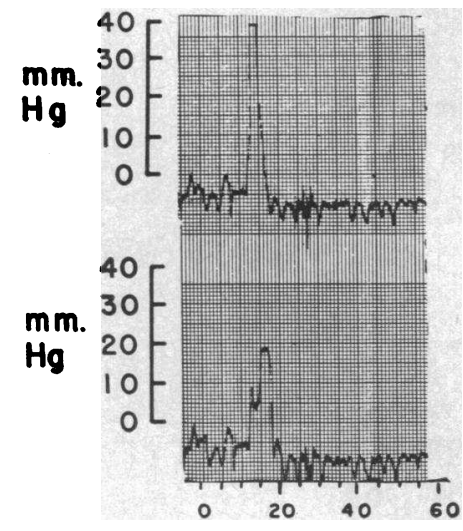

TIME IN SECONDS

Fig. 4. RECORDINGS OF ESOPHAGEAL PERISTALSIS ARE SHOWN DURING THE PAIN-FREE, SALINE-PERFUSION PERIOD AND DURING ACID-INDUCED PAIN. COMparison of the records demonstrates a marked increase in amplitude and duration of peristaltic contraction during the symptomatic period.

heartburn, spontaneously occurring symptoms were produced by acid perfusion, but not by saline. Symptoms were produced in none of the controls. In all cases where esophageal symptoms were induced, motor abnormalities were observed in the lower esophagus (Table IV). These consisted of three types. The first type of motor abnormality observed was increased amplitude and duration of peristaltic contractions (Figure 4). During the period of acid perfusion when the patients experienced pain and heartburn, the amplitude and duration of peristaltic contractions increased to as much as twice that observed in the pain-free period. These motor changes occurred in 24 of the 25 patients with heartburn. The second type observed consisted of nonprogressive esophageal contractions which were spontaneous and did not occur in response to a swallow (Figure 5). Such contractions, occurring at two points $5 \mathrm{~cm}$ apart at exactly the same time, represented spastic, nonperistaltic contractions. These were associated with an increased severity of symptoms. This motor abnormality occurred in 23 of the 25 patients. The third motor abnormality was increased esophageal tone as manifested by a gradual increase in intraluminal pressure (Figure 6). This was observed in 25 of the 25 patients.

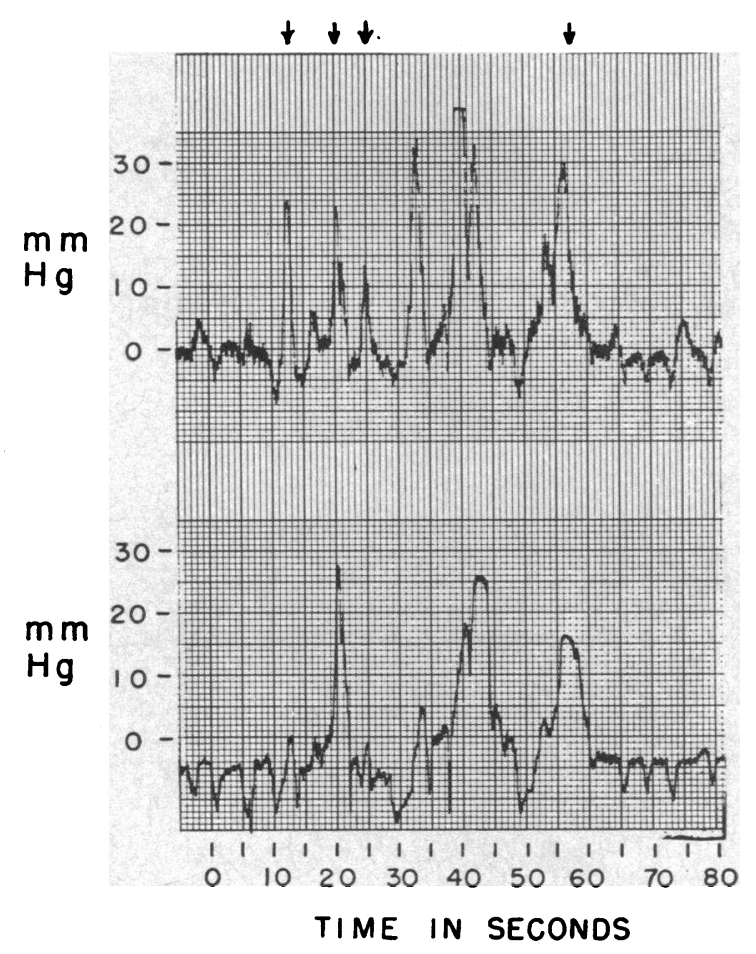

Fig. 5. NONPROGRessive ESOPHAGEAL CONTRACTIONS (INDICATED BY ARROWS) OCCURRED DURING PERIODS OF ACID-INDUCED SYMPTOMS IN 23 OF THE 25 PATIENTS. These nonperistaltic contractions occurred without antecedent swallows and represented localized or segmental contractions. 
SALINE

NO PAIN

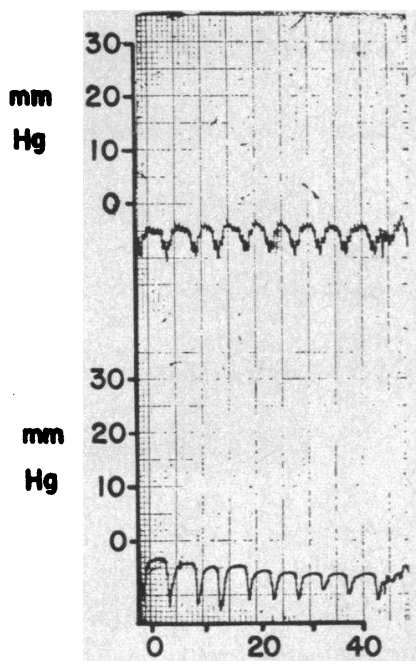

$0.1 \mathrm{~N} . \mathrm{HCl}$

PAIN

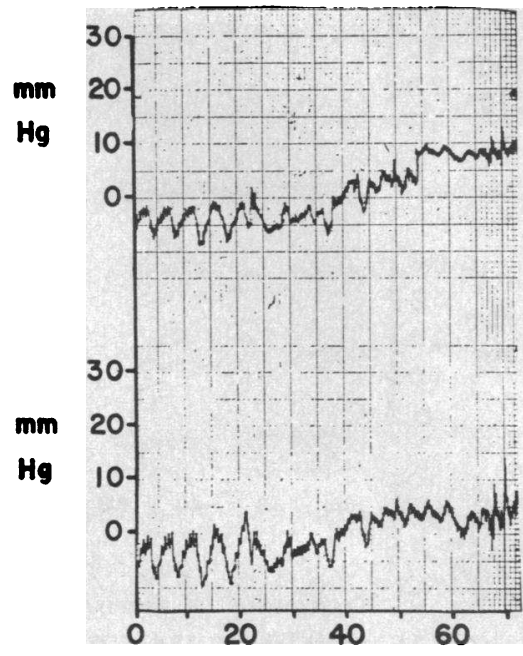

TIME IN SECONDS

Fig. 6. InCREASEd ESOPHAGEAL TONE DURING ACID-INDUCED PAIN. During saline perfusion, no pain was experienced and the intraluminal pressure remained at a constant level. With acid-induced symptoms, intraluminal pressure gradually rose, so that without either peristaltic or nonprogressive contraction, an elevated resting pressure was maintained. In the absence of other motor activity, this change may reasonably be assumed to reflect a rise in tone of the esophageal wall.

\section{(RECORDING TIPS $5 \mathrm{~cm}$. APART)}

SALINE NO PAIN

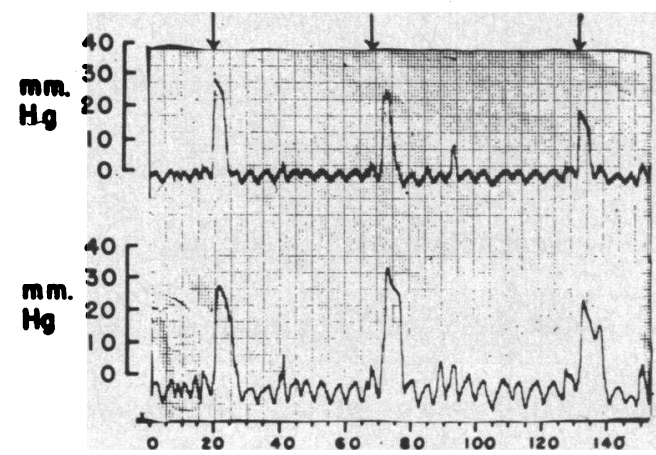

TIME IN SECONDS

\section{$0.1 \mathrm{~N} \mathrm{HCl}$ PAIN}

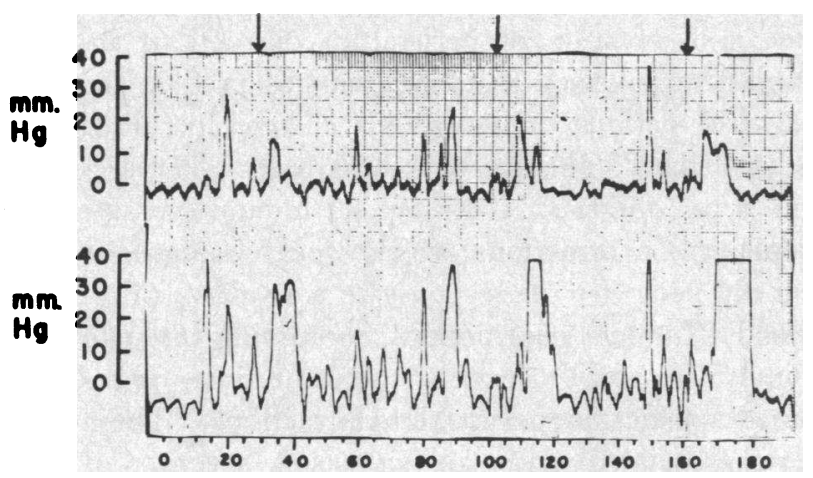

TIME IN SECONDS

Fig. 7. A Characteristic Motor ReCording from a PoSitive acid-PERfusion test. During the pain-free, salineperfusion period (on the left), there is no motor activity other than that initiated by swallows (indicated by arrows). The recording on the right, from the acid-perfusion period with induced pain, shows all three types of motor abnormalities described. 
Motor abnormalities of one or more of the types described above were observed in four of the 25 controls. These motor abnormalities were not associated with symptoms. In two subjects, motor abnormalities were present during the saline as well as the acid-perfusion periods, and thus, not truly acid induced. They occurred as sporadic motor abnormalities in contrast to the sustained motor activity observed during the symptomatic periods in the heartburn group.

A characteristic motor recording obtained from a patient with acid-induced pain is shown in Figure 7. During the pain-free saline perfusion, motor activity appeared in the esophagus only in response to swallows, and each response was peristaltic. During the period of acid-induced pain, on the other hand, a great deal of spontaneous motor activity was observed unrelated to swallowing. Much of this spontaneous motor activity was not peristaltic.

The extent of the motor abnormalities paralleled the severity of the symptoms. In a number of the patients motor abnormalities were present before the patient volunteered that symptoms had developed. As the motor abnormalities grew more marked, symptoms appeared as though a threshold had been exceeded.

\section{DISCUSSION}

It is generally accepted that reflux of gastric juice into the lower esophagus plays a role in the pathogenesis of esophagitis. This has focused attention on the nature of the mechanism that normally prevents gastroesophageal reflux. Three mechanism are postulated $(1,2)$ : one entails the existence of a "flap-valve" at the gastroesophageal junction (3); a second mechanism postulates a "pinchcock" action on the right crus of the diaphragm (4); and the third stresses the primary role of the intrinsic sphincter in the lower esophagus (5-8). Although the anatomic demonstration of a sphincter in this location is not readily performed, manometric data have clearly demonstrated a zone that maintains an elevated resting pressure and relaxes as the peristaltic wave approaches (9). The evidence for the lower esophageal sphincter being the principal barrier to reflux is considerable (10-12). Experimental surgical studies have shown that displacement of the gastroesophageal junction to above or below the level of the hiatus of the diaphragm will not, by itself, promote reflux. However, the excision of the "vestibule," the zone in which the sphincter is located, will regularly lead to severe esophagitis. In patients with hiatus hernia, Atkinson, Edwards, Honour, and Rowlands (13) have shown that the occurrence of symptoms correlates very closely with the amplitude of the resting pressure of the lower esophageal sphincter. Those patients with a hiatus hernia who had a normal lower esophageal sphincter were free of symptoms despite the abnormal location of the gastroesophageal junction. Among the patients in our series both with and without hiatus hernia, the correlation of occurrence of symptoms and a diminished resting pressure of the lower esophageal sphincter is a close one (Figure 3). In $96 \%$ of patients with frequent and persistent burning retrosternal pain. a mean intrasphincteric pressure of only $3 \mathrm{~mm} \mathrm{Hg}$ or less was found. In $76 \%$ of patients without reflux symptoms, the intrasphincteric pressure was greater than $3 \mathrm{~mm} \mathrm{Hg}$. The available data strongly support the premise that the lower esophageal sphincter constitutes the principal barrier to reflux, but the role of other factors, such as the integrity of the phrenicoesophageal ligament, requires further study.

Bernstein and associates $(14,15)$ and Tuttle, Bettarello, and Grossman (16) proposed acid perfusion of the esophagus as an objective test for the localization of the origin of chest pain. Reproduction of the patient's symptoms with acid perfusion constituted evidence for the esophageal origin of these symptoms. An inflammatory process has been suggested as the basis of the symptoms of these patients. In those cases where endoscopic changes were not found, it was reasoned that microscopic inflammatory changes were present (14). However, upon obtaining esophageal biopsies in our 25 patients with heartburn and typical clinical features of esophagitis, no histologic evidence of inflammation was found in biopsies from seven patients. Conversely, of eight patients in the asymptomatic control group from whom biopsies were taken, three showed histologic evidence of chronic inflammation. The poor correlation between the presence of inflammation and the occurrence of symptoms renders improbable the idea that an inflammatory process is essential 
for the mediation of symptoms attributed to esophagitis.

Acid perfusion of the lower esophagus in patients with severe and persistent heartburn consistently reproduces their symptoms. In our experience, these induced symptoms have uniformly been accompanied by motor abnormalities. Conversely, regardless of the presence or absence of histologic evidence of inflammation, patients without esophageal symptoms have not experienced symptoms in response to $0.1 \mathrm{~N} \mathrm{HCl}$ perfusion. Four patients in the control group had minor motor abnormalities during acid perfusion, but these were not associated with symptoms and occurred with equal frequency and magnitude in the saline-perfusion periods. Thus the symptom of heartburn correlates more closely with acid-induced pain and motor abnormalities than with X-ray, endoscopic, or histologic abnormalities.

Three types of motor abnormalities were induced by acid perfusion in patients with heartburn (Table IV). These acid-induced motor abnormalities were associated with either a transient or a prolonged aggravation of burning pain, an association that further enhances the likely role of motor abnormalities in the mediation of these symptoms. This view, which is contrary to most recent thinking, was advanced by Jones (17) many years ago. He induced heartburn by rapid distention of the lower esophagus. His fluoroscopic observations revealed motor abnormalities of the lower esophagus that he interpreted as reverse peristalsis, but were, in all likelihood, produced by nonprogressive contractions of the distal esophagus. Several observers, on the other hand, have not found motor abnormalities in association with reflux symptoms, but these negative observations may be accounted for in part by differences in technique, such as the use of the upright position and higher rates of perfusion (18). Nagler and Spiro (19) in their study of heartburn of pregnancy minimized the role of motor abnormalities in the genesis of heartburn. It should be noted, however, that they demonstrated motor abnormalities in all three patients who had heartburn during their manometric studies. In one of their illustrations, esophageal motor abnormalities disappeared at the time heartburn ceased.

Perfusion of $0.1 \mathrm{~N} \mathrm{HCl}$ is a convenient and re- producible way of mimicking reflux. However, hydrochloric acid is not necessarily the sole noxious substance in gastric secretions ; indeed, erosive esophagitis has been described in patients with achlorhydria (20).

The formulation of the basis for the symptoms of heartburn entails two factors. The first is reflux of an irritating material facilitated by decreased tone of the lower esophageal sphincter. The second is the reactivity of the distal esophagus to the refluxed material, which is manifested by motor abnormalities. Further, the reactivity of the distal esophagus may vary in a given individual both in response to therapy and to other unknown factors, accounting for the intermittent character of these symptoms. As indicated above, symptoms may occur in the absence of inflammatory changes, and marked inflammation may be present without symptoms. Thus reflux of a noxious material into the esophagus and increased reactivity of the distal esophagus to such material, rather than inflammation, are the basic factors in the development of heartburn.

\section{SUMMARY}

A study was performed correlating clinical, endoscopic, histologic, and acid-perfusion studies with intraluminal manometric recording in 25 patients with heartburn who, from their histories, were thought to have esophagitis. Histologic evidence of inflammation was found in only 18 of the 25. These patients were compared with a group of 25 patients with no esophageal symptoms. Acid perfusion produced substernal pain in all the patients in the heartburn group but in none of the controls. Motor abnormalities were observed in all patients in whom acid perfusion reproduced symptoms, suggesting that disordered motor function plays a role in the production of these esophageal symptoms. From these studies it is evident that the symptom of heartburn correlates more closely with reactivity of the esophagus to perfused acid than to the presence of inflammation. The common denominator in these patients is an esophagus which, due to an as yet unknown mechanism, is unduly reactive to refluxed gastric contents. This abnormal reactivity is manifested by heartburn and concomitant esophageal motor abnormalities. 


\section{REFERENCES}

1. Ingelfinger, F. J. Esophageal motility. Physiol. Rev. 1958, 38, 533.

2. Botha, G. S. M. Mucosal folds at the cardia as a component of the gastroœsophageal closing mechanism. Brit. J. Surg. 1958, 45, 569.

3. Von Gubaroff, A. Über den Verschluss der menschlichen Magens an der Cardia. Arch. Anat. Entwickl.-Gesch. 1886, 395.

4. Jackson, C. The diaphragmatic pinchcock in so-called "cardiospasm." Laryngoscope (St. Louis) 1922, 32, 139.

5. Fleshler, B., T. R. Hendrix, P. Kramer, and F. J. Ingelfinger. Resistance and reflex function of the lower esophageal sphincter. J. appl. Physiol. 1958, $12,339$.

6. Fyke, F. E., Jr., C. F. Code, and J. F. Schlegel. The gastroesophageal sphincter in healthy human beings. Gastroenterologia (Basel) 1956, 86, 135.

7. Pert, J. H., M. Davidson, T. P. Almy, and M. H. Sleisenger. Esophageal catheterization studies. I. The mechanism of swallowing in normal subjects with particular reference to the vestibule (esophago-gastric sphincter). J. clin. Invest. 1959, 38, 397.

8. Vantrappen, G., E. C. Texter, Jr., C. J. Barborka, and J. Vandenbroucke. The closing mechanism at the gastroesophageal junction. Amer. J. Med. 1960, 28, 564 .

9. Atkinson, M., D. A. W. Edwards, J. A. Honour, and E. N. Rowlands. Comparison of cardiac and pyloric sphincters. A manometric study. Lancet 1957, $2,918$.
10. Ingram, P. R., J. C. Respess, and W. H. Muller, Jr. The role of an intrinsic sphincter mechanism in the prevention of reflux esophagitis. Surg. Gynec. Obstet. 1959, 109, 659.

11. Braasch, J. W., and F. H. Ellis, Jr. The gastroesophageal sphincter mechanism: an experimental study. Surgery 1956, 39, 901.

12. Ingram, P. R., R. K. Keswani, and W. H. Muller, Jr. A correlative histopathologic study of experimental surgical reflux esophagitis. Surg. Gynec. Obstet. 1960, 111, 403.

13. Atkinson, M., D. A. W. Edwards, A. J. Honour, and E. N. Rowlands. The osophagogastric sphincter in hiatus hernia. Lancet 1957, 2, 1138.

14. Bernstein, L. M., and L. A. Baker. A clinical test for esophagitis. Gastroenterology 1958, 34, 760.

15. Bernstein, L. M., R. Pacini, R. C. Fruin, and E. Gorrett. Esophagitis as a cause of upper abdominal pain. J. Amer. Med. Ass. 1958, 168, 27.

16. Tuttle, S. G., A. Bettarello, and M. I. Grossman. Esophageal acid perfusion test and a gastroesophageal reflux test in patients with esophagitis. Gastroenterology 1960, 38, 861.

17. Jones, C. M. Digestive Tract Pain. New York, Macmillan, 1938.

18. Tuttle, S. G., F. Rufin, and A. Bettarello. The physiology of heartburn. Ann. intern. Med. 1961, 55, 292.

19. Nagler, R., and H. M. Spiro. Heartburn in late pregnancy. Manometric studies of esophageal motor function. J. clin. Invest. 1961, 40, 954.

20. Palmer, E. D. Subacute erosive ("peptic") esophagitis associated with achlorhydria. New Eng. J. Med. 1960, 262, 927. 